Int. J. Electrochem. Sci., 13 (2018) $5810-5823$

\title{
Corrosion inhibition of N80 steel simulated in an oil field acidification environment
}

\author{
Juan Du ${ }^{1, *}$, Jianhua $\mathrm{Guo}^{2}$, Liqiang Zhao ${ }^{1}$, Yixin Chen ${ }^{1}$, Changlong Liu ${ }^{1,3}$, Xianghai Meng ${ }^{3}$ \\ ${ }^{1}$ School of Petroleum and Natural Gas Engineering, State Key Lab, Southwest Petroleum University, \\ Chengdu, Sichuan 610500, P R of China; \\ ${ }^{2}$ Engineering Technology Research Institute of Southwest Oil And Gas Field Company Petro china, \\ Chengdu, Sichuan 610017, P R of China; \\ ${ }^{3}$ CNOOC China Co. Ltd. Tianjin branch, Tianjin 300000, P R of China; \\ *E-mail: dujuanswpu@163.com
}

doi: $10.20964 / 2018.06 .69$

Received: 26 December 2017 / Accepted: 5 March 2018 / Published: 10 May 2018

\begin{abstract}
In this paper, the corrosion process of acidizing fluid $\left(10 \% \mathrm{HCl}+8 \% \mathrm{HBF}_{4}\right)$ in the production string was analyzed according to the acidizing procedure of the running pipe column. The amount of corrosion inhibitor, concentration of displacement fluid $\left(\mathrm{NH}_{4} \mathrm{Cl}\right)$ and off-time $(\mathrm{H})$ were investigated via an orthogonal design method to analyze the influence of the inhibition of acid corrosion of the immobile pipe string to confirm the main factors for corrosion of the oil tube. The results demonstrated that the amount of inhibitor was key to avoid corrosion of the immovable string by acidizing fluid. The corrosion and inhibition properties of N80 steel in fresh acid and residual acid solution were studied through electrochemical measurements and immersion tests. In addition, the corrosion morphology of the corrosion product was examined by scanning electron microscopy (SEM). The results showed that the N80 steel was more seriously corroded in the residual acid than in fresh acid. The pipe string also was corroded by the high-concentration acid liquid during acidification flow-back of the immobile pipe string. Therefore, effective measures should be taken to reduce corrosion due to residual acid on the pipe during the initial stage of acidizing flow-back.
\end{abstract}

Keywords: $\mathrm{N} 80$ steel; acidizing; $10 \% \mathrm{HCl}+8 \% \mathrm{HBF}_{4}$; fresh acid; spent acid; corrosion behavior

\section{FULL TEXT}

(C) 2018 The Authors. Published by ESG (www.electrochemsci.org). This article is an open access article distributed under the terms and conditions of the Creative Commons Attribution license (http://creativecommons.org/licenses/by/4.0/). 